\title{
No effect of Pindolol on postural hypotension in Type 1 (insulin-dependent) diabetic patients with autonomic neuropathy. A randomised double-blind controlled study
}

\author{
A. Dejgård ${ }^{1}$ and J. Hilsted ${ }^{2}$ \\ 'Hvidere Hospital, Klampenborg, and Department of Internal Medicine F, Glostrup Hospital, Denmark
}

\begin{abstract}
Summary. Orthostatic hypotension is one of the most troublesome symptoms in diabetic autonomic neuropathy. Some reports have suggested Pindolol - a beta-adrenoceptor antagonist with intrinsic sympathomimetic activity - to be effective in the treatment of this condition. In order to elucidate the value of this therapy we performed a double-blind placebo controlled cross-over study with Pindolol $(15 \mathrm{mg} /$ day). Eight Type 1 (insulin-dependent) diabetic patients with autonomic neuropathy and signs and symptoms of orthostatic hypotension (systolic blood pressure decrease greater than $30 \mathrm{~mm} \mathrm{Hg}$ when standing) participated in the study. Patients were treated for 10 weeks. Clinical examinations were per-
\end{abstract}

formed every fortnight and patients registered postural symptoms twice daily on a visual analog scale. No significant changes were seen in blood pressure recordings, heart-rate or visual analog scale registration during treatment with Pindolol compared to placebo. Our study does not support the suggestion that Pindolol is a valuable drug for treatment of diabetic patients with autonomic neuropathy and postural giddiness.

Key words: Autonomic neuropathy, orthostatic hypotension, diabetes mellitus, Pindolol treatment, beta receptor blockade.
Autonomic failure is a well-known complication of long-standing diabetes mellitus, and orthostatic hypotension is one of the most inconvenient symptoms. Treatments including withdrawal of exacerbating drugs, tilting the head of the bed to stimulate the renin angiotensin aldosterone system and adapting cerebral vessels to low perfusion pressure, and eventually, fulllength elastic stockings to increase venous return should be tried; but these procedures are seldom of therapeutical value [1]. Plasma volume expansion with fludrocortisone may be effective [2] but recumbent hypertension and cardiac failure are often contradicting side-effects. Additionally, the dopaminergic antagonist metoclopramide and the prostaglandin synthesis inhibitor indomethacin have been recommended [3, 4]. It has been suggested in uncontrolled studies that Pindolol, a beta-adrenoceptor antagonist with a high degree of intrinsic sympathomimetic activity could be therapeutically effective in patients with severe orthostatic hypotension [5-8]. The aim of the present study was to evaluate the effect of Pindolol in a double-blind randomised cross-over study in Type 1 (insulin-dependent) diabetic patients with autonomic failure and symptomatic orthostatic hypotension.

\section{Subjects and methods}

\section{Patients}

All Type 1 diabetic patients with autonomic failure judged by decreased beat-to-beat variation in heart rate during hyperventilation [9] and fall in systolic blood pressure on standing of more than $30 \mathrm{~mm} \mathrm{Hg}$ with coincidental symptoms (dizziness or fainting) were invited to participate in the study. Sixteen patients from our out-patient clinic including 1200 Type 1 diabetic patients fulfilled these inclusion criteria. Six were excluded before the study because of : treatment with antihypertensive drugs ( 2 patients), lack of ability to cope with the study protocol (1 patient), chronic heart failure (1 paticnt) and chronic obstructive airway disease (1 patient) and chronic obstructive airway disease (1 patient). Two of these six patients were unable to stand up due to hypotension. During the study two paticnts were excluded. One patient had become unaware of hypoglycaemia and was admitted twice to the casualty room with severe hypoglycaemia during 1 week of treatment with Pindolol. When Pindolol was withdrawn awareness returned. Another patient was excluded because of severe lung infection associated with cardiac failure. This patient received placebo.

Detailed clinical data of the remaining eight patients who underwent the entire study period are given in Table 1.

\section{Procedures}

The investigation was designed as a randomised double-blind crossover study. 
Table 1. Clinical data of patients studied

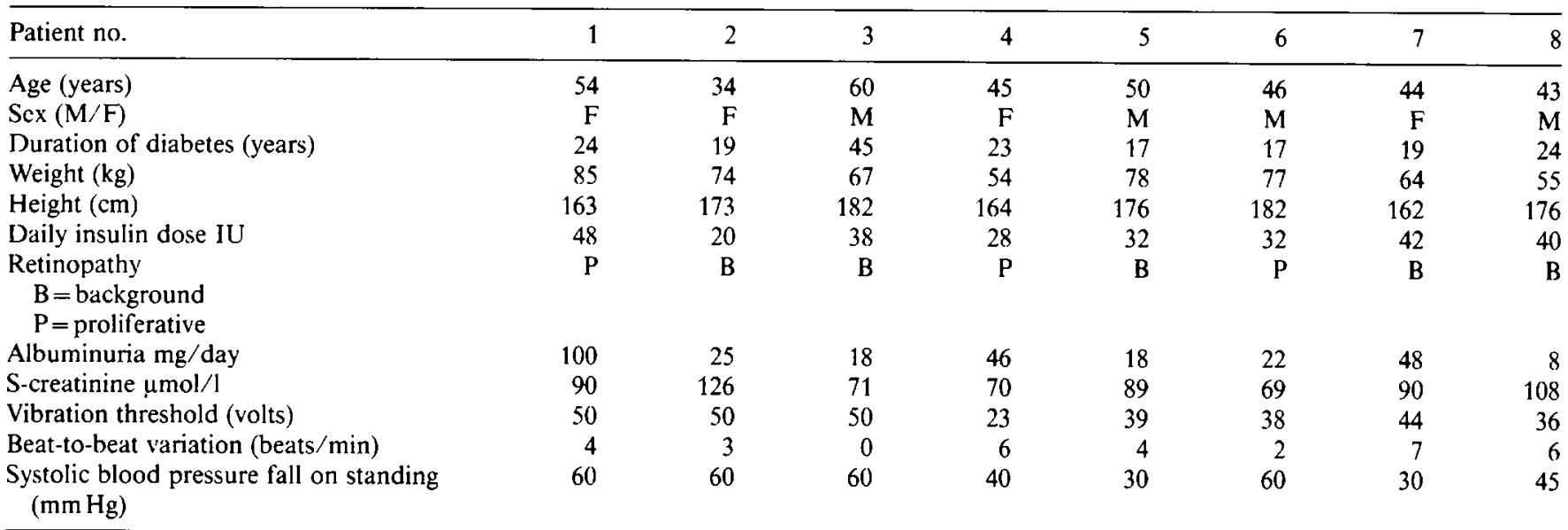

Table 2. Blood pressure and heart rate recording before and during treatment with Pindolol and placebo in supine and standing position (the lowest recording during $10 \mathrm{~min}$ ). Figures are mean values

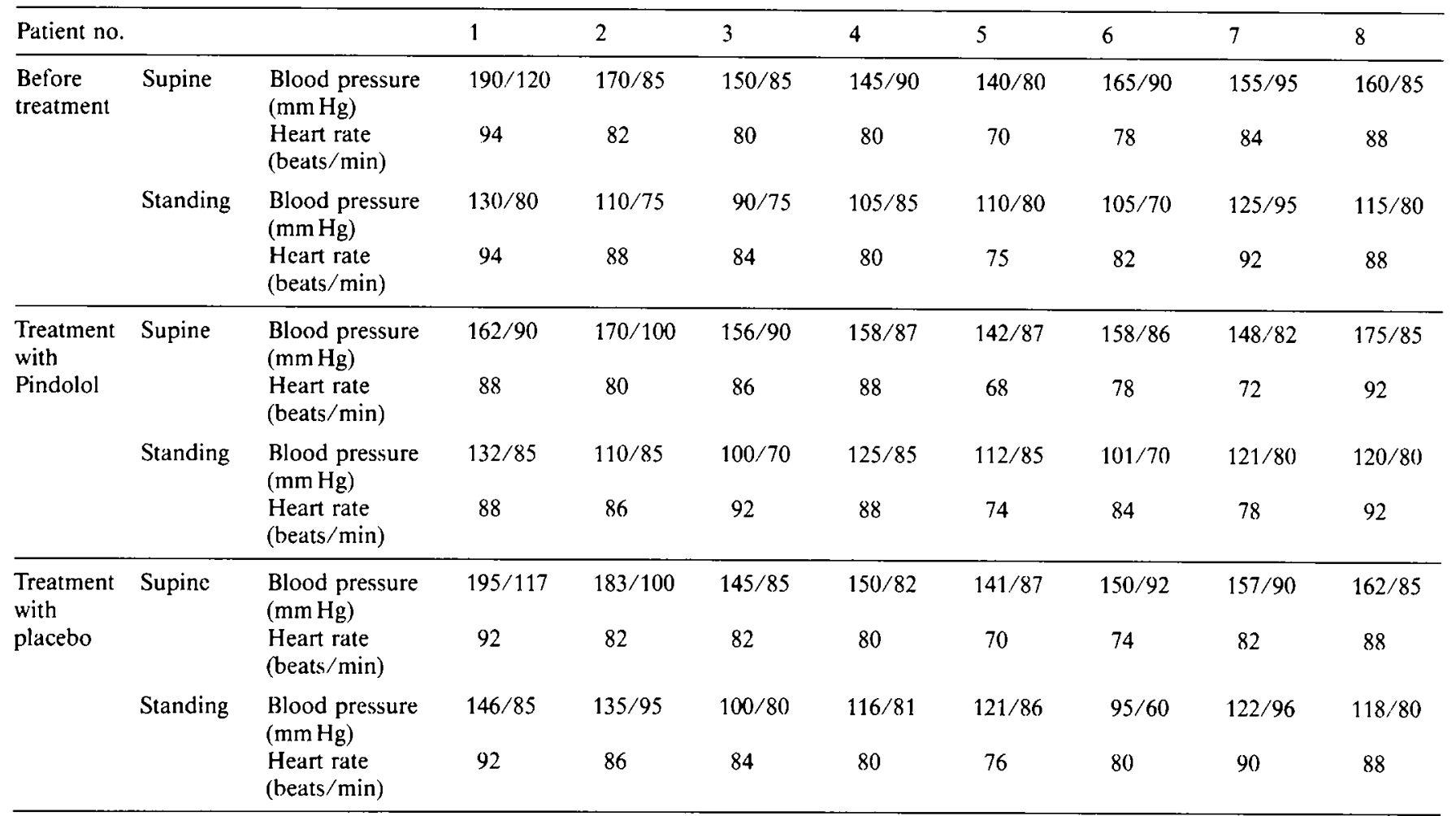

Patients were admitted to the department for 2 days and clinical investigations including ECG, vibratory perception threshold in the big toe measured by a Biothesiometer (Biomedical Instrument $\mathrm{Co}$, Neubury, Ohio, USA), beat-to-beat variation in heart rate and postural blood pressure response were carried out. Blood pressure was measured with a sphygomanometer (Ercameter, N.C. Nielsen, Copenhagen, Denmark) after $15 \mathrm{~min}$ supine rest within $2-4 \mathrm{~h}$ after breakfast and morning insulin. Blood pressure and heart rate recordings were performed supine (twice) and every minute from 0 to $10 \mathrm{~min}$ after standing. Treatment was subsequently started with either Pindolol $5 \mathrm{mg} 3$ times daily or placebo one tablet three times daily. On the second day of admission hypoglycaemia was induced by i.v. injection of fast acting insulin (Actrapid, Novo, Copenhagen, Denmark) in individually adjusted doses until blood glucose was below $2.5 \mathrm{mmol} / \mathrm{l}$ to test awareness. Afterwards patients were examined in our out-patient clinic including clinical examination, beat- to-beat variation on deep breathing and postural blood pressure test once every fortnight for 10 weeks [10].

Starting 1 week before, and during the 10 weeks of treatment patients registered twice daily (at 08.00 and 20.00 hours) the magnitude of their postural complaints on a graphic visual analog rating scalc (VAS) graduated from 0 to $10 \mathrm{~cm}[11], 0 \mathrm{~cm}$ representing no orthostatic symptoms, $10 \mathrm{~cm}$ representing the worst symptoms that the patient could imagine, i. e. syncope. Patients were carefully instructed in the use of VAS in connection with an orthostatic test prior to the study.

To minimize a learning effect patients were instructed to put the individually filled-in VAS registrations in an envelope which was handed over to the investigator at the next out-clinic visit.

Immediately before the start of treatment, and at intervals of four weeks during the study, $\mathbf{H b A}_{1 \mathrm{c}}$ was measured [12]. After 10 weeks of treatment tablets were withdrawn over 4 days and patients were 
without tablets for another 10 days in order to return to bascline in VAS registration. Afterwards a new 10 -week period of treatment with the alternative drug was initiated. This second period of treatment was performed like the first, including the 2 days' admission to hospital initially in the treatment period for clinical investigations and a test for hypoglycaemic awareness. All patients gave informed consent and the investigation was approved by the Local Ethic Committee.

\section{Statistical analysis}

Statistical analyses were performed using McNemar's test, Spearman's rank correlation test and Wilcoxon's test for paired differences. $P$ values less than 0.05 were considered significant.

\section{Results}

\section{Cardiovascular response}

In Table 2 blood pressure readings are given for all patients during treatment with Pindolol and placebo. Supine mean blood pressure was significantly increased in two patients (no. 4 and no. $8, p<0,05$ ), significantly decreased in two patients (no. 1 and no.7, $p<0,05)$ and unchanged in four patients when treated with Pindolol compared to treatment with placebo. There was no significant change in mean blood pressure for all patients as a group between periods when treated with Pindolol $(112 \pm 6)$ and placebo $(117 \pm 16)$ (NS).

During treatment with Pindolol and placebo the mean fall in mean blood pressure on standing was similar (Pindolol: $44 \pm 14 \mathrm{~mm} \mathrm{Hg}$, placebo: $41 \pm 11$, NS). Likewise the mean resting heart rate was similar during the two treatment periods (Pindolol $83 \pm 4$ beats $/ \mathrm{min}$, placebo $86 \pm 5$ beats $/ \mathrm{min})$.

\section{Postural symptoms}

Results of the visual analog rating scale registration are given in Table 3. During treatment with Pindolol VAS registration was improved (more than $15 \mathrm{~mm}$ ) in 3 patients (no.1, no. 3 and no.4), worsened (more than $15 \mathrm{~mm}$ ) in 2 patients (no. 2 and no.5) and unaffected $( \pm 15 \mathrm{~mm})$ in 3 patients compared to treatment with placebo. All patients registered only minor changes in

Table 3. Results of registration on visual analog scale (VAS) twice daily before and during treatment with pindolol and placebo. Values are mean with $\mathrm{SD}$ in brackets

\begin{tabular}{lcccccccc}
\hline $\begin{array}{l}\text { Patient } \\
\text { no. }\end{array}$ & 1 & 2 & 3 & 4 & 5 & 6 & 7 & 8 \\
\hline $\begin{array}{l}\text { Before } \\
\text { treatment }\end{array}$ & 5.1 & 2.2 & 3.8 & 3.6 & 2.1 & 2.1 & 6.0 & 2.8 \\
Treatment & & $(0.1)$ & $(0.2)$ & $(0.2)$ & $(0.1)$ & $(0.3)$ & $(0.3)$ & $(0.1)$ \\
$\begin{array}{l}\text { with } \\
\text { Pindolol }\end{array}$ & 3.2 & 4.7 & 3.1 & 1.3 & 2.3 & 2.3 & 5.9 & 3.0 \\
$\begin{array}{l}\text { Treatment } \\
\text { with }\end{array}$ & 4.6 & 1.7 & 4.6 & 2.8 & 0.2 & 1.8 & 6.3 & 3.1 \\
placebo & $(0.3)$ & $(0.2)$ & $(0.4)$ & $(0.3)$ & $(0.1)$ & $(0.3)$ & $(0.4)$ & $(0.3)$ \\
\hline
\end{tabular}

VAS, all with mean changes of less than $3 \mathrm{~cm}$. None of the patients with improvement in VAS-registration during treatment with Pindolol were completely without symptoms. There was no correlation between VAS-registration and changes in blood pressure during the 2 periods of treatment.

The metabolic control evaluated by $\mathrm{HbA}_{1 \mathrm{c}}$ was identical in the 2 periods of treatment. $\mathrm{HbA}_{1 c}$ was $9.6 \pm 1 \%$ and $9.7 \pm 1 \%$ during treatment with Pindolol and placebo, respectively. Furthermore, no changes were seen in beat-to-beat variation during deep breathing (Pindolol compared to placebo, NS).

In the hypoglycaemic tests performed initially in the treatment periods no differences existed in awareness between periods of Pindolol or placebo treatment. In both situations all patients recognised hypoglycaemia.

\section{Discussion}

In this double-blind placebo controlled study with Pindolol we could not find any significant improvement regarding symptoms and blood pressure responses to standing in diabetic patients with autonomic neuropathy and orthostatic hypotension. Beta-adrenoceptor blocking agents are called partial agonists when the agent after binding to the beta-receptor shows some receptor stimulating properties. This is called intrinsic sympathomimetic activity (ISA) and is a characteristic feature of Pindolol [13]. There have been some reports of a beneficial effect of Pindolol $(15 \mathrm{mg} /$ day $)$ in the treatment of orthostatic hypoten sion in diabetic patients [5-9]. This effect is hypothetically explained by two mechanisms. Firstly, in diabetic patients with autonomic neuropathy the receptor occupancy is in general low, caused by low levels of norepinephrine [14]; and this combined with denervation hypersensitivity of the beta-receptors in the heart theoretically would explain the reported increases in blood pressure and heart-rate with relief of postural symptoms. Secondly, a pure beta-blocking effect with blockade of vasodilatating beta-receptors in striated musculature could increase peripheral vascular resistance and be of beneficial effect in these patients.

In order to maintain cerebral blood flow, neurogenic responses from the baroceptors initiate postural haemodynamic responses. These are an increase in heart rate, increase of cardiac output and an increase of peripheral vascular resistance [15]. Postural hypotension in diabetic patients is mainly due to vasomotor denervation and lack of ability to increase vascular resistance [16], partly due to absent subcutaneous axonreflex [17]. Likewise, these patients have a diminished capacity for increased heart rate and systolic blood pressure during graded exercise [18]. This could indicate target organ failure and a reduced capacity to respond to the ISA of Pindolol. 
The patients in the present study all had rather weak symptoms with rather high standing blood pressures compared to the patients reported where Pindolol had a beneficial effect. Most of these patients had signs of worse sympathetic damage with fainting on standing and upright systolic blood pressures below $100 \mathrm{~mm} \mathrm{Hg}$ [5-9]. In clinical practice these patients are rare. Evidently, long-term diabetic patients with severe autonomic failure have a high incidence of concomitant diseases giving contraindications to beta-adrenoceptor blocking agents (e.g. cardiac failure due to cardiomyopathy and/or arteriosclerotic heart disease). It is worth noting that among the 1200 Type 1 patients in our clinic we included every patient with orthostatic symptoms; none had severe symptoms, including fainting, without contraindication to beta-blockade, e.g. heart failure.

Judging from the heart rate measurements the ISA of Pindolol is inversely correlated to the activity of the sympathetic nervous system [19]. Although blood pressure was not taken into account in the latter study - in contrast to the present study - it cannot be excluded that the lesser effect of Pindolol in our study was due to a comparatively mild sympathetic defect in our patients.

With the present design of the study, and especially the long (10 weeks) duration of treatment, fluctuation in symptoms and blood pressure are eliminated; and even with the rather few blood pressure recordings there is no need to believe that our results are a consequence of a statistical type-II error supported by the lack of improvement in VAS registration performed twice daily.

It is well-known that beta-blocking agents have some rather serious side-effects in diabetic patients like masking signs and symptoms of hypoglycaemia and prolongation of recovery from hypoglycaemia. One of our patients was excluded because of these side-effects. Although this study was not designed to study the effect on hypoglycaemia, no other patient complained of unawareness or more frequent severe hypoglycaemia when treated with Pindolol. Other serious side-effects are cardiac failure and impairment of peripheral arterial circulation [20]. Findings similar to ours, with failure of Pindolol, and even worsening of symptoms in some patients with orthostatic hypotension, have been reported previously [21, 22].

The response to intravenous Pindolol might be a good indicator of the expected response to oral Pindolol [8], but more investigation has to be done to select patients with orthostatic hypotension for treatment with Pindolol.

\section{References}

1. Editorial (1981) Management of orthostatic hypotension. Lancet I: $963-964$

2. Campbell JW, Ewing DJ, Clarke BF (1976) Therapeutic experience with fludrocortisone in diabetic postural hypotension. $\mathrm{Br}$ Med J 1: 872-874

3. Kuchel O, Bun NT, Gutkowska J, Genest J (1980) Treatment of severe orthostatic hypotension by metoclopramide. Ann Intern Med 93: 841-843

4. Kochar MS, Itskovitz HD (1978) Treatment of idiopathic orthostatic hypotension (Shy-Drager Syndrome) with indomethacine. Lancet I: 1011-1014

5. Frewin DB, Leonello PP, Penhall RK, Harding PE (1980) Pindolol in orthostataic hypotension. Med J Aust 1:128

6. Man in't Veld AJ, Boomsma F, Schalekamp MAIJH (1982) Effects of $\mathrm{B}$-adrenoceptor agonists and antagonists in patients with peripheral autonomic neuropathy. $\mathrm{Br} \mathrm{J}$ Clin Pharmacol 13: 367 S-374 S

7. Man in't Veld AJ, Schalekamp MADH (1981) Pindolol acts as a beta-adrenoceptor agonist in orthostatic hypotension. Therapeutic implications. Br Med J 282: 929-931

8. Robson D (1981) Pindolol in postural hypotension. Lancet II: 1280

9. Boesen F, Andersen EB, Kanstrup J, Hesse B, Christensen NJ (1982) Treatment of orthostatic hypotension with pindolol. Acta Neurol Scand 66: 386-391

10. Hilsted J, Jensen SB (1979) A simple test for autonomic ncuropathy in juvenile diabetics. Acta Med Scand 205: 385-387

11. Scott J, Hurkisson FC (1976) Graphic representation of pain. Pain 2: $175-184$

12. Mortensen HB (1980) Quantitative determination of hemoglobin$\Lambda_{1 \mathrm{c}}$ by thinlayer isoelectric focusing. J Chromatogr 182: 325-333

13. Lowenthal DT, Saris SD, Packer J, Haratz A, Lonry K (1984) Mechanisms of action and the clinical pharmacology of beta-adrenergic blocking drugs. Am J Med: 119-127

14. Christensen V.J (1972) Plasma catecholamines in long-term diabetics with and without neuropathy and in hypophysectomized subjects. J Clin Invest 51: 779-787

15. Ziegler MG (1980) Postural hypotension. Ann Rev Med 31: 239-245

16. Hilsted J, Parving H-H, Christensen NJ, Bein J, Galbo H (1981) Hemodynamics in diabetic orthostatic hypotension. J Clin Invest 68: $1427-1434$

17. Hilsted J (1979) Decreased sympathetic vasomotor tone in diabetic orthostatic hypotension. Diabetes $28: 970-973$

18. Hilsted J, Galbo H, Christensen NJ (1979) Impaired cardiovascular responses to graded exercise in diabetic autonomic neuropathy. Diabetes 28: 313-319

19. Tanaka N, Kawahira K, Kudo A, Kashina T, Tanaka H (1982) Dependence of the cardiovascular effect of pindolol on the individual sympathetic nervous activity. Eur $\mathbf{J}$ Clin Pharmacol 22: 383. 387

20. Östman J (1983) Beta-adrenergic blockade and diabetes mellitus. A review. Acta Med Scand [Suppl.] 672: 69-77

21. Goldstraw P, Waller DG (1981) Pindolol in orthostatic hypotension. Br Med J 283: 310

22. Davidson AC, Smith SE (1981) Pindolol in orthostatic hypotension. Br Med J 282: 1704

Received: 9 September 1987

and in revised form: 22 February 1988

Dr. A. Dejgård

Hvidøre Hospital

Emiliekildevej 1

DK-2930 Klampenborg

Denmark 